\title{
A SOMBRA QUE ILUMINA: A POESIA DE ANTÓNIO FRANCO ALEXANDRE
}

\author{
Ricardo Gil Soeiro \\ Universidade de Lisboa
}

"Tenho o gosto do segredo," confessa Jacques Derrida em Il Gusto del Segreto (1997). Com esta arrojada (e aparentemente aporética) confissão, o filósofo francês pretende sublinhar que, se a transparência da inteligibilidade estivesse garantida, arruinaria o texto, demonstrando que este não tem porvir, que não transborda o presente e que se consuma imediatamente. "Se todos podem entender imediatamente o que quero dizer," prossegue, "não criei contexto algum, respondi mecanicamente à expectativa, e está tudo onde está, ainda que as pessoas aplaudam e leiam até com prazer. Depois fecham o livro, e acabou-se."

Ora, num original itinerário poético que inclui Poemas (1996), Quatro Caprichos (1999), Uma Fábula (2001), Duende (2002) e Aracne (2004), António Franco Alexandre evidencia hospitalidade ao porvir. Em Poemas, vai insistindo uma voz que sussurra: "aproximo-me de falar, mas ambiciono/guardar silêncio." É nosso propósito tactear a poesia franco alexandrina, sabendo que o labor que a anima se demora nesta "fala imperceptível," sempre situada no limiar entre o sim e o não, entre a luz e a sombra, entre a mágoa dos corpos e a redenção do encontro, entre um angustiante e obstinado mutismo das coisas (dos seus "objectos principais") e o horror da sua inviolada transparência.

Porque são as sombras que aqui falam (Wahr spricht, wer Schatten spricht, diz-nos Paul Celan na epígrafe a $A$ Pequena Face), cada poema transforma-se numa "sombra que ilumina/lugar onde nada se vê," expondo-nos a um efeito de murmúrio e a um precário "talvez" que, minando os habituais alicerces discursivos, deixam desarmada qualquer despótica pretensão hermenêutica. Nesta poesia, não há qualquer certeza ou evidência, pois "as evidências matam." Fechamos o livro e começa a promessa do sentido. 
Este culto da incerteza não passou despercebido à maioria dos críticos. Se para Joaquim Manuel Magalhães, "as palavras com que nos faz partilhar o seu enfrentamento de mundo, a densidade emocional com que nos lembra a exaltante mágoa do encontro dos corpos, a encantação de que nos faz testemunhas e participantes, fazem da sua obra poética um dos exemplares trágicos do esquecimento a que a nossa recente poesia se encontra votada" (Magalhães 1981, 251), já Gastão Cruz se reportará ao seu feliz carácter elíptico (Cruz 1999, 180-181). E se o também poeta Luís Miguel Nava se refere a "um discurso deliberadamente opaco, alheio ao propósito de comunicar quaisquer sentidos prévios" (Nava 2004, 270), Fernando Pinto do Amaral falará, por sua vez, de um "efeito de murmúrio," de um mágico e terno silêncio, que deflui das palavras de António Franco Alexandre (Amaral 1991, 106).

$\mathrm{Na}$ fascinante interpretação de George Steiner, os poetas não são filhos de Apolo, mas sim de Mársias. Tendo arracadado a flauta que Atena repudiara, e julgando que a sua música era a mais bela do mundo, Mársias desafiou Apolo a que, com a sua lira, criasse uma música semelhante. Este aceitou o repto, com a condição de que o vencedor tivesse liberdade de infligir ao vencido o tratamento que desejasse. Tendo as musas declarado Apolo vencedor, o deus amarrou Mársias a um pinheiro e esfolou-o vivo. $\mathrm{Na}$ apreciação steineriana deste episódio mitológico, se falar (isto é, assumir a privilegiada singularidade e solidão do homem no silêncio da criação), é perigoso; falar com a força máxima da palavra como faz o poeta, é sumamente perigoso —o silêncio é, pois, um refúgio quando Apolo está por perto. No seminal ensaio "The Silence and the Poet," incluído em Language and Silence (1967), Steiner declara:

Gradually, this ambivalence in the genius of language, this notion of the god-rivaling, therefore potentially sacrilegious character of the act of the poet, becomes one of the recurrent tropes in Western literature. From Medieval Latin poetry to Mallarmé and Russian Symbolist verse, the motif of the necessary limitations of the human word is a frequent one. It carries with it a crucial intimation of that which lies outside language, of what it is that awaits the poet if he were to 


\section{A Sombra que Ilumina}

transgress the bounds of human discourse. Being, in the nature of his craft, a reacher, the poet must guard against becoming, in the Faustian term, an overreacher. The daemonic creativity of his instrument probles the outworks of the City of God; he must know when to draw back lest he be consumed, Icarus-like, by the terrible nearness of a greater making, of a Logos incommensurable with his own (in the garden of fallen pleasures, Hieronymus Bosch's poet is racked on his own harp) (Steiner 1967, 39).

$\mathrm{Na}$ verdade, como o próprio António Franco Alexandre nos confidencia, o poema constitui "um sopro só, rumor," "breve sopro, às vezes" $(2002,58)$, um sopro de sentido em que, sem gesto redentor, "as palavras falam, sem barulho" (2004, 16). De Uma Fábula a Aracne, passando por As Moradas e por Duende, as suas composições poéticas quebram igualmente a normal articulação discursiva, produzindo estilhaços de múltiplos discursos em trânsito e em metamorfose permanentes. Em Uma Fábula (2001), um quarteto assombroso constituído por "Poemas Simples," "Duplo," "Eco" e "Epimítio" e a primeira visitação de Franco Alexandre ao universo das Metamorfoses ovidianas, assiste-se ao desvanecimento das vozes que imbrica o leitor numa multiplicidade de enredos que inviabiliza a descoberta de um sujeito poético claramente identificável: "o eco calado/de cego narciso, sem/nunca encontrar na mensagem/mais do que a pálida imagem/do seu jeito de ninguém" (2001, 12-13) e, no mesmo livro, o seguinte testemunho com um clara ressonância pessoana: "Já não serve de nada a poesia/a literária 'arte de chiar.' E quanto a pensamento: esse schelling/já me moeu o siso. Desisti de entender/a 'identidade.' Pense quem lê" (2001, 53). Como declara Gilles Deleuze, "[t]odas as identidades não são senão simulacros, produzidas como um efeito óptico, por um jogo mais profundo, que é o da diferença e da repetição" (Deleuze 1968, 1). Rosa Maria Martelo advogará que, a partir da publicação de Quatro Caprichos, a poesia franco alexandrina tem vindo a manifestar de um modo cada vez mais intenso um certo pendor narrativo que, embora permita ao leitor traçar amiúde um retrato do sujeito lírico que se eleva assim a um quase estatuto de personagem, o rosto do sujeito lírico dissolve-se, 


\section{Ricardo Gil Soeiro}

dando lugar à emergência de um Outro. Em Quatro Caprichos, lemos:

Não tinhas, reparei, "identidade." Faltara-te, ou perderas. identikit, umbigo de fabrico, carte de séjour; só ficaram as marcas distintivas de um humano rosto, e depois também elas se apagaram ou multiplicaram nos humanos gesto amados, e na cegueira do humano desejo desejado, da palavra "tu” $(1999,57)$.

Também em Duende (2002), explorando magistralmente as virtualidades formais do soneto, Franco Alexandre despede-se das certezas cristalizadas e abraça a transfiguração do real: "La verdadera lucha es con el duende," lê-se na epígrafe colhida de Lorca, assim confirmando o esbatimento entre a verdade e a fantasia, entre sonho e realidade, entre aspiração e desilusão:

Já a luz se apagou do chão do mundo, deixei de ser mortal a noite inteira; ofensa grave a minha, que tentei misturar-me aos duendes na floresta. De máscara perfeita, e corpo ausente, a todos enganei, e ninguém nunca saberia que ainda permaneço deste lado do tempo onde sou gente. Não fora o gesto humano de querer-te como quem, tendo sede, vê na água o reflexo da mão que a oferece, seria folha de árvore ou sério gnomo absorto no silêncio de uma rima onde a morte cessasse para sempre $(2002,38)$.

Formalmente irrepreensível, este poema fala-nos do desejo e do fracasso, da alegria do sim na tristeza do finito e, ainda assim, deixa-nos desarmados e vulneráveis - invadidos pela sensação de que somos incapazes de falar sobre a sua demanda poética. Já em 2004, Franco Alexandre regressa à atmosfera ovidiana, oferecendo-nos Aracne. De acordo com a história narrada por Ovídio nas Metamorfoses, no Canto VI, Aracne, declarando-se superior à própria deusa tutelar da tecelagem, Minerva, é desafiada por esta a participar numa prova de tapeçaria: enquanto Minerva constrói uma tela mitológica que representa a sacralidade dos deuses, Aracne 


\section{A Sombra que Ilumina}

produz uma tapeçaria em que os deuses assomam como modelos de lascívia e concupiscência. Enraivecida, Minerva castiga Aracne, transformando-a em aranha. Este episódio mitológico constitui o ponto de partida para a uma elegíaca celebração da palavra poética, em que o inusitado rigor formal convive com a intensidade emotiva, criando-se uma atmosfera em que os objectos do real são filtrados como que através de um véu, cuja espessura se adensa num imperceptível "quase" que invade a própria substância da comunicação poética, volvida em rumor indizível e situada à margem do magistério das palavras:

Sombra de um verso, não sei como possa

ter bom sucesso neste meu projecto

de te fazer meu cúmplice leitor;

uma vírgula mais talvez mudasse

o sentido do mundo, mas duvido

que uma tão ténue pausa chegue ao teu ouvido (2004, 27-28).

Como observamos, a poesia franco alexandrina alimentase de uma lúcida fenomenologia do impreciso, precariamente edificando múltiplas cartografias mentais a partir da circunstacialidade da experiência amorosa e da vivência urbana, embora transfigurando-as num profundo e radical testemunho poético, do qual avulta o exercício da liberdade poética: desarrumação da linguagem em Sem Palavras nem Coisas (1974), gravidade reminiscente da tradição bíblica sapiencial de alguns poemas de As Moradas 1 \& 2 (1987), a intensidade imagista de Visitação (1983), bem como a errância discursiva quando retoma a tradição do poema longo em Oásis (1992) ou "Poema Simples" (incluído em Uma Fábula) e à exuberância lúdica de Quatro Caprichos.

Certo é que a noção de testemunho que esta poesia põe em cena é deveras complexa: em larga medida, diria que é pósmoderna e pós-humanista. Na verdade, órfão de Nietzschepara quem o sujeito que pensa constitui não mais do que o mero resultado de uma ilusão de gramática - o pensamento pós-moderno, que se quer declaradamente pós-humanista, despede-se do sujeito humano como último baluarte da tirania da metafísica da presença. Paralelamente à morte de Deus - que nos forçou à visão de um céu desamparado que 
sobre nós se abateu, submetendo-nos ao vento fresco das mais altas montanhas que Zaratustra experimentará-a proclamação da morte do homem por Michel Foucault, em Les Mots et les choses (1966), ecoou como anúncio de uma nova época no pensamento que inevitavelmente irá desaguar no crepúsculo do Homem - "um rosto de areia na praia, prestes a ser varrido pelas ondas." Se a atitude humanista nos convida a pensar o ser humano como mestre e senhor incontestado da acção, a viragem anti-humanista interrogará os privilégios concedidos ao cogito, quer no triunfo cartesiano do cogito, ergo sum, quer na sua versão idealista. Nessa nova paisagem ouvem-se diversas vozes: Claude Lévi-Strauss afirma que "o objectivo último das ciências humanas não é tanto constituir o homem, mas sim o de o dissolver" (1962, 326); para Jacques Lacan, "où ça parle l'homme n'existe plus"; por sua vez, Martin Heidegger, na famosa Carta Sobre o Humanismo, vaticina que estamos numa situação em que há principalmente o Ser e não o sujeito; para Derrida, tudo se resume à écriture, sendo que também o ser humano pode ser definido como estando, desde sempre, inscrito na linguagem, o que nos permite pensar numa concepção de subjectividade que se afasta da substância ou identidade meta-linguística, um cogito puro ou auto-presença. Maurice Blanchot, esse, debruçar-se-á sobre a literatura e o direito à morte. Nesta verdadeira waste land da teoria pós-humanista, Nietzsche pergunta: “Quem fala?” É a própria palavra, responde Mallarmé. Paradoxalmente, todavia, esta viragem semiótica nas ciências humanas veio problematizar, de um modo decisivo, quer a radicação ontológica da linguagem, quer a densidade da subjectividade cartesiana. Cada vez mais, a linguagem abraça menos mundo. Cada vez mais, Narciso é habitado por múltiplas vozes.

Ainda assim, gostaria de precisar que mesmo o cepticismo mais resoluto não pode deixar de formular a sua contestação no próprio instrumento de comunicação que pretende questionar. Em termos análogos, Vítor Manuel Aguiar e Silva argumenta: 


\section{A Sombra que Ilumina}

De Beckett a Artaud, de Bataille a Blanchot, multiplicam-se os textos em que obsidiantemente se confrontam a necessidade da utilização da linguagem e a radical impossibilidade dessa utilização, em que se pratica e exalta o desfiguramento e a destruição do texto-algumas vezes com um fascínio horrorizado que participa da violência e do êxtase profanatórios-em que se afirma a solidão essencial do acto de escrever, a identidade inconsútil do espaço da morte e do espaço literário, a abolição e o vazio do significado como ideal da linguagem e da literatura: "Le langage ne commence qu'avec le vide; nulle plénitude, nulle certitude ne parle" [o autor cita Blanchot em La Part du Feu].

Paradoxalmente, esta dramática reflexão sobre a incomunicabilidade e a solidão radical da obra de arte, sobre a exaustão significativa da linguagem, sobre o silêncio mortal e o vazio de que é urdida a textura do poema-reflexão nascida de uma desesperada tensão entre um orfismo condenado ao fracasso e um hermetismo cruelmente niilista - realiza-se, configura-se semicamente e é comunicada através de obras de arte, nas palavras, nas metáforas, nas frases e no ritmo da linguagem verbal e, de modo particular, da linguagem literária. Mesmo quando se postula que a interioridade de cada homem é incomunicável a outro homem ou que o real das coisas é incognoscível ao homem, a obra de arte comunica aquela incomunicabilidade e diz esta incapacidade cognitiva. Se a obra de arte se caracterizasse, em estrito rigor, pelo hermetismo monadológico de que fala Adorno, ela constituiria necessariamente um enigmático facto bruto, um vazio berrante ou, se se quiser, uma plenitude absurda (Aguiar e Silva 1999, 195-196).

Quero defender que é deste paradoxo que se alimenta continuamente a poesia franco alexandrina. Voltando-se para o mundo, embora dele se afastando quando este é considerado numa acepção excessivamente simplista, esta poesia resulta, pois, "largamente ilegível" (Américo Lindeza Diogo), na medida em que dá ordem de despejo ao mundo e a sua estranha e fulgurante gramática opera o luto da mimese. Todavia, é-nos confidenciado que a poesia está ainda em devir, fulgurando como um cálculo de rotas inexactas: "Julgavas então que a poesia era um discurso de palavras em sentido?" Como defende Carlo Vittorio Cattaneo, Franco Alexandre "refuta [...] um conceito cartesiano de realidade e, tendo renunciado às 'certezas,' pode disfrutar tranquilamente a riqueza operativa das 'possibilidades" (qtd. in Amaral 1991, 107). Em Sem Palavras nem Coisas, justamente a este respeito, lemos: 
minhas pequenas dúvidas enumeram os dentes,

conhecem hegel, ultrapassam

obliquamente os pulsos, procuram

habitação inerte.

minhas pequenas dúvidas [...]

vestem à pressa os ossos, aguardam

a rotação inútil dos planetas,

vigiam as estrelas moídas na garganta (Alexandre 1996, 34).

Com efeito, não estamos perante um sentido prévio a reproduzir. Pese embora se anuncie em As Moradas que:

cabe-me agora a descrição cuidada

do mundo em que vivemos

tal descrição, e o testemunho que ela envolve, jamais obedece à tradicional exigência de uma inteligibilidade linear:

esta esquisita prova me tentou

de tecer um rumor em muros de água

ossos de terra calcinada

o jugo

culpado me castigo com engenho

e da voz desenhada o artifício

restos de pele antiga

no laço da armadilha

em silêncio me muro e me demoro

no cálculo de rotas inexactas

em duro arbítrio quer que me desprenda

dos cincos ou mais sentidos

vou ser livre na terra desnudada

vou dizer o que sei como quem mente (Alexandre 1996, 175).

Neste sentido, a subtil modalização operada pelo advérbio "talvez" e a importância do "quase" nesta ars poetica são sinais manifestos desta fenomenologia poética do impreciso. Por outro lado, Franco Alexandre abre mão de diversos recursos estilísticos que concorrem para a criação do efeito de estranheza desejado: a utilização de sinestesias ("eu simplesmente ouvi a luz do vento" em Visitação) e de 


\section{A Sombra que Ilumina}

oxímoros vívidos ("pois tenho em ti o fixo rumo incerto" em Duende), o uso do hipérbato ("segredava-te, do tempo o vão aspecto" em Quatro Caprichos) e de hipálages ("as luzes escancaradas do silêncio" em Sem Palavras nem Coisas), bem como as diversas inovações linguísticas, quer ao nível vocabular (quando funde duas palavras já existentes como em "madrugadanoite" em Sem Palavras nem Coisas ou "noitarder" e ainda "cegamante" em Pequena Face), quer ao nível da insólita subversão de sintagmas preposicionais ("dormíamos dentro um do um" em As Moradas) e da infracção intencional de regras gramaticais ("estas algumas horas" em Os Objectos Principais).

Neste contexto, importa, através de um breve excurso que se me afigura frutuoso, reflectir sobre a afinidade electiva entre a poesia franco alexandrina e a poesia de Paul Celan. No âmbito da presente reflexão, importaria dar ressonância ao que de mais essencial esta afinidade alberga. Não podendo intentar tão longa travessia, limitar-me-ei a sugerir que, apesar de um mundo que os separa, a demanda poética de ambos brota da dialéctica entre ausência e presença, entre fracasso e promessa, entre vacuidade e plenitude, entre emudecimento e encontro. Efectivamente, se há obra poética ameaçada pelo emudecimento, essa obra será a poesia de Paul Celan. Conduzido ao limiar do dizível e habitando um (aparentemente) paradoxal "princípio dialógico," é porque nenhuma palavra das já ditas lhe serve que Celan se encerrará num (quase) impenetrável silêncio como se estivesse a ocultar o mais terrível dos segredos, silêncio que (como bem sabia Kafka) é mais fatal do que o canto. ${ }^{1}$ Como último a falar (é esse o título de um ensaio que Maurice Blanchot lhe

\footnotetext{
${ }^{1}$ Temos em mente obviamente as palavras de Kafka: "Nun haben aber die Sirenen eine nach schrecklichere Waffe als den Gesang, nämlich ihr Schweigen" (Kafka 1961, 300). Sobre o pequeno texto de Kafka, cf. A. P. Foulkes. "An Interpretation of Kafka's 'Das Schweigen der Sirenen'." Journal of English and Germanic Philology (1965): 98-104 e Heinz Politzer. "Das Schweigen der Sirenen." Das Schweigen der Sirenen. Studien zur deutschen und österreichischen Literatur. Stuttgart. J. B. Metzlersche. 1968. 13-18. Cf. igualmente a análise de Maurice Blanchot. "Le Chant des Sirènes." Le Livre à Venir. Paris: Gallimard. 1959. 9-37.
} 


\section{Ricardo Gil Soeiro}

dedica ${ }^{2}$ ), a Celan é indeclinável a descida a esse silêncio, viagem simultaneamente penosa e indispensável. A palavra poética volve-se agora em segredo, pois a experiência humana-em particular depois da auto-condenação a que o sujeito humano se votou em Auschwitz - respira, ofegantemente, no magma obscuro do inominável e do sem-sentido. Porque se constituiu como base cognitiva tendo em vista acções brutais e desumanas (demasiado humanas?), a linguagem é incapaz de dizer o mundo. Todavia, e o paradoxo agudiza-se, "como não falar?," interroga-se - enquanto fala-Derrida. ${ }^{3}$ Certeiro, pois, o parecer de Lyotard para quem

é impossível edificar o que quer que seja de e sobre estes escombros. Só podemos atravessá-los, deslizar por entre as ruínas, ouvir o lamento que delas emana, ecoá-lo. [...] O que a arte pode fazer é prestar testemunho não do sublime mas dessa aporia da arte e da sua dor. Ela não diz o indizível, diz que não pode dizê-lo. "Depois de Auschwitz" é necessário, como é a intenção de Elie Wiesel, acrescentar ainda um versículo à história do esquecimento do recolhimento junto do fogo na floresta (Célébration, 173). Não posso atear o fogo, não conheço a oração, já não consigo encontrar o lugar na floresta, já nem sequer sei contar a história. Tudo aquilo que sei fazer é contar que já não sei contar essa história (Lyotard 1999, 74, 79).

O poema nada pode, apenas certifica quão impotente e inane é.

Não nos surpreende que, na sequência de um cruzamento entre o orfismo de Mallarmé e o ontologismo da linguagem de Heidegger, diversos críticos tenham inscrito a poesia celaniana na linhagem de uma poética do hermetismo e da opacidade de que Valéry, Ungaretti, Gottfried Benn ou René Char seriam os seguidores paradigmáticos (Hölderlin seria uma outra figura tutelar em Celan e Nelly Sachs chega a atribuir ao poeta o epíteto de "o Hölderlin do nosso tempo," sendo que exegetas como Phillipe Lacoue-Labarthe e

\footnotetext{
${ }^{2}$ Cf. Maurice Blanchot. "Le Dernier à Parler." Une Voix Venue d'ailleurs. Paris: Éditions Gallimard. 2002. 69-105.

${ }^{3}$ Cf. Jacques Derrida. "Comment ne pas parler: denegations." Psyché: Inventions de l'autre. Paris: Galilée. 1987. 535-595. Ver igualmente o seguinte texto: J. L. Marion. "Au nom: Comment ne pas parler de 'théologie négative'." Laval théologique et philosophique (1999): 339-363.
} 


\section{A Sombra que Ilumina}

Vincenzo Vitiello não hesitam em filiá-lo na linhagem hölderliniana da "poesia da poesia"). Ora, parece-me que Celan, influenciado pela filosofia dialógica de matriz judaica (pensamos nomeadamente em Martin Buber e Franz Rosenzweig, mas também em Emmanuel Lévinas), se furta a esta leitura unívoca que, na esteira do que é também a proposta de Adorno, nele surpreende um irmão gémeo de Beckett e corifeu de um hermetismo desumanizado.

Por certo, não é possível rasurar a dimensão dialógica da poesia de Celan, de que, de resto, os seus textos poetodológicos como Der Meridian ou Gespräch im Gebirge (este último marcado pela sombra de Adorno, o "judeu Grande," que impõe a sua lei do silêncio) são os testemunhos iniludíveis. A meu ver, a palavra celaniana, obedecendo a um movimento "que vai do seu Já-não ao seu Ainda-e-sempre," é verdadeiramente uma Gegenwort ("contra-palavra"), uma palavra da contra-di(c)ção que se converte num acto de uma profunda e incontornável liberdade "que já não se curva diante dos "cavalos de parada nem dos pilares da História." O tão glosado hermetismo de Celan (que Primo Levi chegou a repudiar, classificando a sua linguagem de obscuraadjectivo também, não raras vezes, aplicado à escrita de Franco Alexandre) mais não é do que uma inexorável recusa de contaminação pela doxa ou pela Gerede. Tendo plena consciência da decisão ética que tomou, justamente a de escrever numa língua carregada de "palavras homicidas," simultaneamente a da mãe e a dos seus carrascos, Celan, abjurando uma poética autolelicamente fechada sobre si mesma, prefere ver os seus poemas como uma mensagem numa garrafa ou um singelo e desafectado aperto de mãos, caminhando ao encontro de um absolutamente Outro: "Mas o poema fala! Mantém viva a memória das suas datas, mas fala." Jacques Derrida, em Schibboleth. Pour Paul Celan, tematizará esta problemática, "o 20 de Janeiro"-data em que Lenz, a figura büchneriana que anda "de cabeça para baixo, tendo o céu por abismo," parte para as montanhas, mas também a data da conferência de Wansee, em que foi deliberada a Endlösung — que se inscreve em cada poema. 


\section{Ricardo Gil Soeiro}

A poesia de Franco Alexandre dimana de uma sombra que ilumina: não raras vezes, o sujeito poético procura convencer o seu leitor de que "o poema é inútil como uma criança," rogando-lhe "não creias nas palavras." Todavia, acolhendo "a sombra dos segredos," a palavra não renuncia, ainda assim, a pressentir o "pequeno rumor da eternidade." Insistese numa comunicação quase sempre falhada, mas esta jamais é abandonada (daí a presença quase obsessiva dos telegramas, do envelope, das cartas ou do cartão-postal).

O sopro, a sombra, o laço, a água, o espelho, o silêncio, a errância-todos estes topoi partem em busca de uma "verdade a meio aberta, repetida,/como a suspensa vibração de nada." O sujeito poético que daqui emerge é um cogito ferido (na formulação luminosa de Paul Ricoeur), um cogito que pouco mais é do que "pouco nítido holograma," testemunhando que "há um lugar incerto onde aconteço." Assiste-se, pois, a uma dissolução do sujeito no real que o envolve: "misturo-me às coisas menos profundas" ou "dissolvo-me na sombra da paisagem,/separo-me de nós, de mim, serei quase/a chama no carvão que fica ardendo," esbatendo-se igualmente as fronteiras epistemológicas entre sujeito cognoscente e objecto cognoscível:



Gostaria de dedicar o último fôlego da presente reflexão a Derrida e ao seu gosto pelo segredo a que inicialmente fiz menção e que agora recupero. Em textos como Passions e Che cos'è la poesia, bem como em Donner la Mort, o pensador francês, declarando o seu amor pela literatura, 


\section{A Sombra que Ilumina}

confidencia-nos que o segredo é o que não responde, o que recusa toda a resposta frente a uma autoridade qualquer, e isso constitui a sua própria singularidade, irredutível a qualquer fala: "Ele não responde à fala, ele não diz 'Eu, o segredo,' ele não corresponde, ele não dá garantia: nem dele, nem a ninguém, nem diante de quem ou do que quer que seja" (Derrida 1993, 62). O segredo é, pois, a não-resposta absoluta, permanecendo estranho à fala, não se lhe reduzindo. $\mathrm{O}$ amor pela literatura tende então para a possibilidade de dizer tudo guardando segredo. Em Papier Machine, Derrida assegura que "a instituição da literatura reconhece, em princípio ou por essência, o direito de dizer tudo ou de não dizer dizendo, daí o direito ao segredo ostentado. A literatura é livre. Deveria ser. A sua liberdade é também aquela que uma democracia promete" (Derrida 2001, 398). Na óptica derridiana, o segredo da escrita é um segredo paradoxal já que é em definitivo inexistente:

La littérature garde un secret qui n'existe pas, en quelque sorte. Derrière un roman ou un poème, derrière ce qui est en effet la richesse d'un sens à interpréter, il n'y a pas de sens secret à chercher. Le secret d'un personnage, par exemple, n'existe pas, il n'a aucune épaisseur en dehors du phénomène littéraire. Tout est secret dans la littérature et il n'y a pas de secret caché derrière elle, voilá le secret de cette étrange institution au sujet de laquelle, et dans laquelle je ne cesse de (me) débattre (Derrida 2000, 21).

Em Résistances, Derrida convoca Bartleby, de Herman Melville, como a figura da morte e de uma "resistência" à análise. Nele se pode surpreender o "o segredo da literatura," isto é, o segredo que resiste à resposta desveladora que nos tranquiliza a sede dos sentidos previstos e já mapeados:

Nous sommes là de retour au plus près de l'ombilic du rêve, en ce lieu où le désir de mort et le désir tout court appellent et disent l'analyse qu'ils interdisent, la disent en ne disant rien, répondent sans répondre, sans dire oui ni non, sans accepter ni s'opposer, en parlant cependant mais sans rien dire, ni le oui ni le non, comme Bartleby The Scrivener. À toute demande, question, pression, requête, ordre, il répond sans répondre, ni passif ni actif: 'I would prefer not to', je préférerais ne pas... Ceux qui ont lu ce petit livre immense de Melville savent que Bartleby est 


\section{Ricardo Gil Soeiro}

aussi une figure de la mort, certes, mais aussi que, sans rien dire, il fait parler, et d'abord le narrateur qui se trouve être aussi un homme de loi responsable et un analyste infatigable. En vérité incurable. Bartleby fait parler l'analyste comme narrateur et homme de loi. Bartleby, c'est aussi le secret de la littérature (Derrida 1996, 38).

Em distinto contexto, mas em testemunho não menos intenso, também John Caputo nos fala do segredo da literatura. Em "Hermeneutics and the Secret," Caputo declara que a literatura é o segredo exemplar para Derrida. Filhos da mesma noite escura, todos nós somos possuídos pelos mesmos demónios e assombrados pelos mesmos espectros e, apesar dessa fria verdade, nenhum de nós pode garantir que tem em sua posse o conhecimento da Verdade ou do Sentido. Como Kierkegaard, Derrida ou o próprio Caputo, ficamos à espera dos fragmentos que caem da secretária de Hegel enquanto este urde a sua leitura sistemática da história mundial. Afirmar que não sabemos O Segredo é o mesmo que dizer que, por muito que tentemos, não podemos fazer remontar a nossa origem a uma fonte divina ou infinita. Afirmá-lo, porém, não significa dizer que tal fonte não existe: significa tão-só reconhecer humildemente que todos nós, como "pobres indivíduos existentes" que somos, somos incapazes de alcançá-la:

\footnotetext{
"Literature" is the exemplary secret for Derrida, just because we are there deprived, absolutely and paradigmatically, of the luxury of laying aside the text and taking a peek around the curtain of signs to see what is really going on. [...] The structural nonknowing, "blindness," or unreadibility by which we are beset in virtue of the absolute secret is what gives us passion. We are driven by the passion of non-knowing. Our readings and interpretations, our rereadings and conflicting interpretations, are like so many fingers clinging tenaciously to the edge of the cliff. Instead of arresting the play of meaning, a more radical or more originary experience of hermeneutics faces up to the inescapable play of interpretation, which is all we have to hang on to as our feet dangle dangerously over the rushing rapids below (Caputo 2000, 3).
}

Assim é a poesia de António Franco Alexandre, sem nome primordial que em si tudo contenha e que em si tudo 


\title{
A Sombra que Ilumina
}

aprisione, engrandecida por uma sombra que ilumina, despedindo-se de qualquer verdade comum aos planetas:

\author{
numa noite de audácia incomparável \\ passo a tratar-te por tu, e abraço com as pontas dos dedos \\ os nós das tuas mãos; no fresco calor condicionado \\ de um quarto onde a luz não dá para ler, recito \\ estrofes e mitos; beijo-te, não é? nada estava escrito, \\ nenhuma verdade comum aos planetas, \\ éramos só nós sem nenhum segredo, \\ vivos e completos, serenos, mortais (Alexandre 2001, 73).
}

Bibliografia activa:

Alexandre, António Franco. Poemas. Lisboa: Assírio \& Alvim, 1996.

---. Quatro Caprichos. Lisboa: Assírio \& Alvim, 1999.

---. Uma Fábula. Lisboa: Assírio \& Alvim, 2001.

---. Duende. Lisboa: Assírio \& Alvim, 2002.

---. Aracne. Lisboa: Assírio \& Alvim, 2004.

Bibliografia passiva:

Amaral, Fernando Pinto do. "A Fala Imperceptível de António Franco Alexandre." O Mosaico Fluido. Modernidade e Pós-Modernidade na Poesia Portuguesa mais Recente. Lisboa: Assírio \& Alvim, 1991. 106-118.

---. "A luz que nasce das palavras." Mil Folhas (2001): 10. Antunes, David. "Identidade, metamorfose e fantasmas em Uma Fábula de amor." A Phala 90 (2001): 112-113.

Aurélio, Diogo Pires. "A Pequena Face." O Próprio Dizer. Sobre Poesia, Prosa e Outros Estados de Razão. Lisboa: Imprensa Nacional-Casa da Moeda, 1984. 65-70.

Diogo, Américo António Lindeza. Modernismos, PósModernismos, Anacronismos - Para uma História da Poesia Portuguesa. Lisboa: Cosmos, 1993. 23-41.

---. "Poesia (e) Uniforme (Faria de Sousa, Franco Alexandre, Ramos Rosa, Cervantes." Companhia de Poetas. Pastoral, Cepticismo, Museu Imaginário. Ponte Vedra: Irmandade da Fala da Galiza e de Portugal, 1997. 1-18. 
---. Sem Família. Sobre Poesia de António Franco

Alexandre. Braga: Cadernos do Povo, 2001.

Lopes, Óscar. "Um poema de António Franco Alexandre." Cifras do Tempo. Lisboa: Editorial Caminho, 1990. 323-330.

Lourenço, Frederico. "António Franco Alexandre: Pense quem lê." Os meus livros 2 (2002): 27-30.

---. "Catafonia Visível: Uma Fábula de António Franco Alexandre." Grécia Revisitada. Lisboa: Livros Cotovia, 2004. 273-279.

---. "Insectos Gregos." Público (2005): 14.

Magalhães, Joaquim Manuel. "António Franco Alexandre." Os Dois Crepúsculos. Sobre Poesia Portuguesa Actual e Outras Crónicas. Lisboa: A Regra do Jogo, 1981. 245-250.

Martelo, Rosa Maria. "Metamorfose e repetição-Uma Fábula, de António Franco Alexandre." Em Parte Incerta. Estudos de Poesia Portuguesa Moderna e Contemporânea. Porto: Campo das Letras, 2004. 227-236.

Nava, Luís Miguel. “António Franco Alexandre.” Ensaios Reunidos. Lisboa: Assírio \& Alvim, 2004. 264-284.

Rosa, António Ramos. "António Franco Alexandre ou a íntima violência do exterior." Incisões Oblíquas. Estudos Sobre Poesia Portuguesa Contemporânea. Lisboa: Caminho, 1987. 157-161.

San-Payo, Patrícia. "Recensão a Aracne, de António Franco Alexandre." Românica 14 (2005): 235-238.

Silva, João Amadeu Oliveira Carvalho da. "A poesia de António Franco Alexandre ou 'o signo de uma ausência no fundo das imagens." Revista Portuguesa de Humanidades, Vol. 11, 2 (2007): 97-126.

Outras referências:

Aguiar e Silva, Vítor. Teoria da Literatura. Coimbra: Almedina, 1999.

Blanchot, Maurice. "Le Dernier à Parler." Une Voix Venue d'ailleurs. Paris: Éditions Gallimard, 2002. 69-105. 


\section{A Sombra que Ilumina}

Caputo, John. More Radical Hermeneutics: On Not Knowing Who We Are. Bloomington and Indianapolis: Indiana University Press, 2000.

Celan, Paul. Arte poética. O Meridiano e outros textos. Lisboa: Livros Cotovia, 1996.

---. Sete Rosas Mais Tarde. Antologia Poética. Lisboa: Livros Cotovia, 1996.

---. A Morte é uma Flor. Poemas do espólio. Lisboa: Livros Cotovia, 1998.

Deleuze, Gilles. Différence et répétition. Paris: PUF, 1968. Derrida, Jacques. "La Pharmacie de Platon." La Dissémination. Paris: Seuil, 1972.

---. "Comment ne pas parler: denegations." Psyché: Inventions de l'autre. Paris: Galilée. 1987, 535-595. 291.

---. "Confession." Jacques Derrida. Paris: Seuil, 1991. 5-

---. “Che cos'é la poesia?” Points de Suspension. Paris: Galilée, 1992. 303-308.

---. Passions. Paris: Galilée, 1993.

---. Demeure. Paris: Galilée, 1996. 13-73.

---. Résistances-de la psychanalyse. Paris: Galilée, 1996.

---. "La Littérature au secret: une filiation impossible."

Donner la mort. Paris: Galilée, 1999. 159-209.

---. "Jacques Derrida: 'Autrui est secret parce qu'il est autre'-Entretien d'Antoine Spire avec Jacques Derrida." Le Monde de l'éducation 284 (2000): 21.

---. Papier Machine. Paris: Galilée, 2001.

--- e Ferraris, Maurizio. O Gosto do Segredo. Lisboa: Fim de Século, 2006.

Hassan, Ihab. The Dismemberment of Orpheus. Toward a Postmodern Literature. Madison: The University of Wisconsin Press, 1982.

Kafka, Franz. Erzählungen. Frankfurt am Main: S. Fischer Verlag, 1961.

Lévi-Strauss, Claude. La Pensée Sauvage. Paris: Plon, 1962.

Lyotard, Jean-François. Heidegger e os Judeus. Lisboa: Instituto Piaget, 1999. 


\section{Ricardo Gil Soeiro}

Marion, J. L.. "Au nom: Comment ne pas parler de 'théologie négative." 'Laval théologique et philosophique (1999): 339-363.

Steiner, George. Language \& Silence: Essays on Language, Literature, and the Inhuman. London/Boston: Faber and Faber, 1967. 